Brit. F. vener. Dis. (1968), 44, 116.

\title{
FURTHER OBSERVATIONS ON THE PERSISTENCE OF TREPONEMA PALLIDUM AFTER TREATMENT IN RABBITS AND HUMANS*
}

\author{
BY \\ A. R. YOBS $\dagger$, J. W. CLARK, JR., S. E. MOTHERSHED, \\ J. C. BULLARD, AND C. W. ARTLEY \\ Venereal Disease Research Laboratory, Venereal Disease Program, National Communicable Disease Center, \\ Public Health Service, U.S. Department of Health, Education, and Welfare, \\ Atlanta, Georgia 30333
}

Syphilis in humans was first treated with penicillin more than 23 years ago when four patients with darkfield-positive, sero-positive syphilis were considered cured on the basis of lesion regression and serological conversion (Mahoney, Arnold, and Harris, 1943). One of these men became re-infected and was cured by repeat penicillin treatment (Mahoney, Arnold, and Harris, 1949). The use of penicillin with satisfactory clinical results spread, and by 1954 this drug was being used as the sole form of treatment of venereal syphilis and other treponematoses almost everywhere in the United States (Willcox, 1954).

Although penicillin has won wide acceptance, there have been occasional reports of patients with early syphilis who have not been cured by treatment with recommended schedules of this antibiotic. Such reports have generally been poorly documented and have not excluded the possibility of re-infection. Attempts in vivo to develop a strain of Treponema pallidum resistant to arsenic or penicillin were not successful (Probey, 1948, 1953).

Collart and his co-workers reported the persistence of treponemes in lymph nodes and cerebrospinal fluid of rabbits 1 year after penicillin treatment for late latent syphilis (Collart, Borel, and Durel, 1962a, 1964). These authors reported similar findings in lymph nodes and cerebrospinal fluid from humans treated for late latent syphilis or neurosyphilis with combinations of penicillin, arsenic, and heavy metals (Collart, Borel, and Durel, 1962b; Collart, 1964; Collart and Durel, 1964; Collart, 1965). According to their reports, these treponemes were not all morphologically typical of $T$. pallidum but did infect rabbits on transfer in some cases. Lesions, one of them

\footnotetext{
* Received for publication July 17, 1967.

† Present address: Pesticides Program, National Communicable Disease Center.

NOTE: Trade names are used for identification only and do not represent an endorsement by the Public Health Service or the U.S. Department of Health, Education, and Welfare.
}

darkfield positive, developed in two of the penicillintreated rabbits after a course of cortisone. Del Carpio (1959, 1963), who gave penicillin to rabbits with early latent syphilis and observed them for 5 months, also reported data suggesting treponemal persistence.

Research was undertaken to study treponemes present after treatment of late latent syphilis in order to determine their potential clinical significance. Preliminary results of a study in humans have already been published (Yobs, Rockwell, and Clark, 1964a; Yobs, Olansky, Rockwell, and Clark, 1965). This paper reports results of further study of the human material and of a 4-year study of rabbits treated with penicillin for late latent syphilis. The work consisted of four principal experiments, the first two being performed at the same time. The method and results are presented for each experiment.

\section{Material, Methods, and Results}

Experiment 1 Penicillin-Treated Late Latent Experimental Syphilis in Rabbits (Chart 1, opposite)

The experimental group included 34 rabbits with a history of inoculation with Nichols virulent strain Treponema pallidum 14 to 22 months previously, followed by the development of darkfield-positive lesions and appropriate serological response. All rabbits were infected by inoculation into the testes, except for one in which intracutaneous inoculation was performed; none had received any antibiotics. No lesions attributable to syphilis were present, and there had been no evidence of cuniculosis. All were reactive in the Treponema pallidum immobilization (TPI) test at this time. Reactivity in the quantitative VDRL slide test varied from non-reactive to a maximum reactivity of eight dilutions in one rabbit. VDRL and TPI tests were performed according to the methods recommended in "Serologic Tests for Syphilis" (USPHS, 1964). 

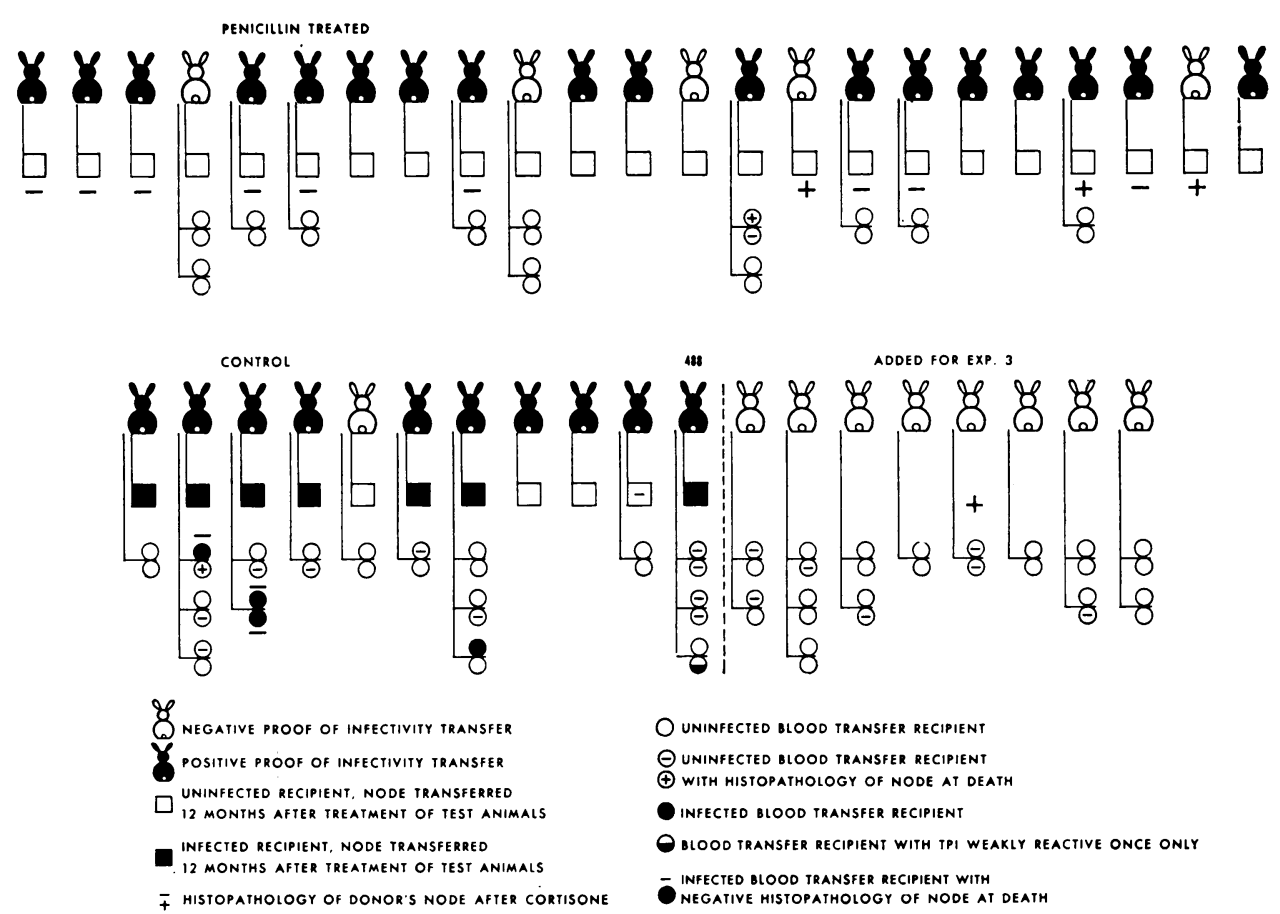

O UNINFECTED BLOOD TRANSFER RECIPIENT

$\Theta$ Uninfected blood transfer recipient

๑ WITH hISTOPATHOLOGY OF NODE AT DEATH

infected blood transfer recipient

O blood transfer recipient with tpi weakiy reactive once oniy

- infected Blood transfer recipient With

negative histopathology of node at death

Chart 1.-Penicillin-treated late latent experimental syphilis in rabbits. Experiment 1 .

Cortisone effect on penicillin-treated late latent experimental syphilis in rabbits. Experiment 3.

PROOF OF INFECTIVITY To confirm the presence of active syphilis, the left popliteal lymph node of each animal was extracted and transferred in suspension to normal rabbits by intratesticular inoculation. Suspensions were prepared by mincing nodal tissue in a small amount of sterile 50 per cent. normal rabbit serum- 50 per cent. physiological saline ( 0.85 per cent.) solution as described (Yobs and others, 1964a). The development of darkfield-positive lesions and of serological response in the recipients proved that 29 donors $(8.53$ per cent.) had been actively infected.

METHOD The 34 donor rabbits were divided into two groups. Each of 23 rabbits (nineteen with darkfieldpositive tissue recipients) received benzathine penicillin $\mathrm{G}$, four injections of 50,000 Oxford units $/ \mathrm{kg}$. body weight at 5-day intervals to a total of 200,000 Oxford units/kg. body weight. A control group of eleven rabbits (ten with darkfield-positive tissue recipients) was not treated. Both groups were then followed clinically for 12 months, and VDRL and TPI tests were performed at 6 and 12 months.

One year after penicillin treatment, eighteen treated and eleven control rabbits survived and were still TPI-reactive. The right popliteal lymph node was removed from each animal. Suspensions prepared from approximately two-thirds of each node were inoculated into the testes of two additional TPI-non-reactive rabbits. These recipients were also followed for 12 months using a regimen of regular clinical observation, frequent darkfield examination of testicular aspirates and fluids from any suspicious areas, and serological testing (VDRL slide test at $1 \frac{1}{2}, 3,6$, and 12 months; and TPI at 6 and 12 months).

The remaining nodal tissue was used for histopathological study. A total of twelve sections of nodal tissue and twelve smears of inoculating suspension, prepared by a silver-staining method (Krajian, 1939; Dieterle, 1927) and a fluorescent-antibody (FA) technique (Yobs, Brown, and Hunter, 1964b), was examined for a minimum of 8 to 9 hours. In addition, darkfield study of residual inoculating suspension was carried out by several microscopists for a total of 2 hours.

\section{Results}

Nodes from seven of eleven control rabbits produced darkfield-positive orchitis in recipients. At the end of 12 months, five of these recipients were TPI-reactive, four were non-reactive, and two had died. No recipients of nodes from the penicillintreated group developed darkfield-positive orchitis or other lesions and, after 12 months, the sixteen survivors were both negative to TPI- and VDRLtests. No treponemes were demonstrated in the nodes of control or treated rabbits by histopathology. 


\section{Experiment 2 Human Studies (Chart 2, oppo- site)}

\section{Summary of Previous Work}

As reported in detail (Yobs and others, 1964a, 1965), a right inguinal lymph node was removed from each of 45 TPI-reactive male volunteers with documentable medical histories of treatment for syphilis. Previous treatment, which had consisted of arsenic, bismuth, and/or penicillin in various combinations, was adequate by current standards in 44 cases.

One man (Patient 20) gave a history of inadequate treatment. An additional (46th) case (Patient 41) had untreated darkfield-positive secondary syphilis on the day before node excision.

These nodes were studied intensively by histopathological techniques and by animal inoculation, and nodes from five of the men who had been treated at some previous time, including the inadequatelytreated patient, were shown to contain $T$. pallidum. Two of these five nodes infected TPI-non-reactive normal rabbits on transfer. Three nodes, including one of those which had infected, were shown to contain $T$. pallidum by FA staining, and the fifth node was positive for $T$. pallidum by silver staining. (The node from the secondary syphilitic did not produce darkfield-positive lesions, but one recipient was TPI-reactive at 6 months.) Possible re-infection could not be excluded.

These five men were re-treated. Depending on clinical criteria, treatment consisted of a total of 4.8 or $7 \cdot 2$ million units of benzathine penicillin $G$, given as intramuscular injections of $2 \cdot 4$ million units at weekly intervals, or $30 \mathrm{~g}$. erythromycin by mouth over 15 days. (The volunteer with secondary syphilis was treated with 2.4 million units of benzathine penicillin $G$ and was then dropped from the study.) A left inguinal lymph node was excised from each of the five men 3 to $3 \frac{1}{2}$ months after treatment, and all were negative for treponemes when studied as before; 15 months after the re-treatment, serological testing of the four still available in this group showed no significant difference from initial test results. Clinical data on these five men are summarized in the upper portion of Table I.

TABLE I

CLINICAL DATA FOR PATIENTS FOUND POSITIVE (11 of 45) BY SOME STUDY PROCEDURE

\begin{tabular}{|c|c|c|c|c|c|c|c|c|c|c|c|c|c|c|c|c|}
\hline \multirow{3}{*}{$\begin{array}{l}\text { Patient } \\
\text { No. }\end{array}$} & \multirow{3}{*}{$\begin{array}{l}\text { Age } \\
\text { (yrs) }\end{array}$} & \multirow{3}{*}{$\begin{array}{c}\text { First } \\
\text { Diagnosis }\end{array}$} & \multirow{3}{*}{$\begin{array}{c}\text { Year and } \\
\text { Drug at } \\
\text { First } \\
\text { Adequate } \\
\text { Treatment }\end{array}$} & \multirow{3}{*}{$\begin{array}{c}\text { Year and } \\
\text { Drug at } \\
\text { Last } \\
\text { Treatment } \\
\text { for } \\
\text { Syphilis }\end{array}$} & \multirow{3}{*}{$\begin{array}{c}\text { Anti- } \\
\text { biotics } \\
\text { since } \\
\text { Last } \\
\text { Syphilis } \\
\text { Treatment }\end{array}$} & \multirow{2}{*}{\multicolumn{3}{|c|}{ Serum Tests† }} & \multicolumn{3}{|c|}{$\begin{array}{l}\text { Cerebrospinal Fluid } \\
\text { at Surgery }\end{array}$} & \multirow{3}{*}{$\begin{array}{c}\text { Re- } \\
\text { treatment }\end{array}$} & \multirow{2}{*}{\multicolumn{3}{|c|}{$\begin{array}{c}\text { Serology } \\
15 \text { mths after } \\
\text { Re-treatment }\end{array}$}} & \multirow{3}{*}{ TPI } \\
\hline & & & & & & & & & \multirow{2}{*}{$\begin{array}{l}\text { VDRL } \\
\text { Slide }\end{array}$} & \multirow{2}{*}{ Coll } & \multirow{2}{*}{$\begin{array}{c}\text { Protein } \\
\begin{array}{c}\text { Content } \\
\text { (mg. } \\
\text { per } \\
\text { cent.) }\end{array}\end{array}$} & & & & & \\
\hline & & & & & & VDRL & dils & KRP & & & & & VDRL & dils & KRP & \\
\hline 10 & 41 & $\begin{array}{c}\text { Early } \\
\text { latent }\end{array}$ & $\begin{array}{c}1932 \\
\mathrm{As}, \mathrm{Bi}\end{array}$ & $\begin{array}{l}1960 \\
\text { Pen }\end{array}$ & & $\mathbf{R}$ & 1 & R4+ & $\mathbf{N}$ & 0 & 40 & $\begin{array}{l}4 \cdot 8 \text { m.u. } \\
\text { Bicillin }\end{array}$ & $\bar{R}$ & 1 & $\overline{\text { R4+ }}$ & $\mathbf{R}$ \\
\hline 12 & 37 & $\begin{array}{l}\text { Early } \\
\text { latent }\end{array}$ & $\begin{array}{l}1947 \\
\text { Pen }\end{array}$ & $\begin{array}{l}1960 \\
\text { Pen }\end{array}$ & & WR & $\mathbf{0}$ & $\mathbf{R 4}+$ & $\mathbf{N}$ & 0 & 51 & $\begin{array}{c}7 \cdot 2 \text { m.u. } \\
\text { Bicillin }\end{array}$ & WR & 0 & $\mathbf{R 4 +}$ & $\mathbf{R}$ \\
\hline 20 & 42 & $\begin{array}{c}\text { Late } \\
\text { latent }\end{array}$ & $\begin{array}{l}1947 \ddagger \\
\mathrm{As}, \mathrm{Bi}\end{array}$ & Same & $\begin{array}{c}1960 \text { Ery- } \\
\text { thromycin } \\
1961 \text { Terra- } \\
\text { mycin }\end{array}$ & $\mathbf{N}$ & 0 & $\mathbf{R} \mathbf{1}+$ & QNS & 0 & 27 & $\begin{array}{l}30 \text { gm. } \\
\text { Erythro- } \\
\text { mycin }\end{array}$ & $\mathbf{N}$ & $\mathbf{0}$ & $\mathbf{R 2}+$ & $\mathbf{R}$ \\
\hline 22 & 34 & $\underset{\text { genital }}{\text { Con- }}$ & $\begin{array}{c}1944 \\
\mathrm{As}, \mathrm{Bi}\end{array}$ & $\begin{array}{l}1955 \\
\text { Pen }\end{array}$ & & $\mathbf{R}$ & 4 & R3+ & QNS & 0 & 17 & $\begin{array}{l}4 \cdot 8 \text { m.u. } \\
\text { Bicillin }\end{array}$ & & N.A. & & \\
\hline 29 & 36 & Secondary & $\begin{array}{l}1951 \\
\text { Pen }\end{array}$ & $\begin{array}{l}1959 \\
\text { Pen }\end{array}$ & $\begin{array}{c}1961 \\
\text { Penicillin }\end{array}$ & WR & 0 & R4+ & $\mathbf{N}$ & 0 & 41 & $\begin{array}{l}4 \cdot 8 \mathrm{~m} . \mathrm{u} \\
\text { Bicillin }\end{array}$ & WR & 0 & R4+ & $\mathbf{R}$ \\
\hline 16 & 51 & Primary & $\begin{array}{c}1931 \\
\text { As }\end{array}$ & $\begin{array}{c}1941 \\
\mathrm{As}, \mathrm{Bi}\end{array}$ & & WR & 0 & $\mathbf{N}$ & $\mathbf{N}$ & 0 & 32 & N.D. & & N.D. & & N.D \\
\hline 21 & 53 & $\begin{array}{l}\text { Late } \\
\text { latent }\end{array}$ & $\begin{array}{l}1948 \\
\text { Pen }\end{array}$ & $\begin{array}{l}1961 \\
\text { Pen }\end{array}$ & & WR & 0 & $\mathbf{R} \mathbf{1}+$ & QNS & 0 & 50 & N.D. & & N.D. & & N.D \\
\hline$* 23$ & 29 & $\underset{\text { genital }}{\text { Con- }}$ & $\begin{array}{l}1940 \\
\text { Pen }\end{array}$ & $\begin{array}{l}1949 \\
\text { Pen }\end{array}$ & & WR & 0 & $\mathbf{N}$ & QNS & $\mathbf{0}$ & 16 & N.D. & & N.D. & & N.D \\
\hline 26 & 34 & Primary & $\begin{array}{c}1950 \\
\text { As, Bi }\end{array}$ & $\begin{array}{l}1954 \\
\text { Pen }\end{array}$ & $\begin{array}{c}1961 \\
\text { Penicillin }\end{array}$ & WR & 0 & $\mathbf{N}$ & $\mathbf{N}$ & 0 & 24 & N.D. & & N.D. & & N.D \\
\hline 38 & 38 & Secondary & $\begin{array}{l}1939 \\
\text { As, Bi }\end{array}$ & Same & & $\mathbf{R}$ & 1 & R4+ & $\mathbf{N}$ & 0 & 35 & N.D. & & N.D. & & N.D \\
\hline 43 & 43 & Secondary & $\begin{array}{l}1943 \\
\mathrm{As}, \mathrm{Bi}\end{array}$ & $\begin{array}{l}1960 \\
\text { Pen }\end{array}$ & & $\mathbf{N}$ & 0 & $\mathrm{~N}$ & $\mathbf{N}$ & 1 & 25 & N.D. & & N.D. & & N.D \\
\hline \multicolumn{17}{|c|}{$\begin{array}{l}\text { *hite. } \\
\text { † All TPI-reactive. } \\
\text { N.D. Not done. }\end{array}$} \\
\hline
\end{tabular}



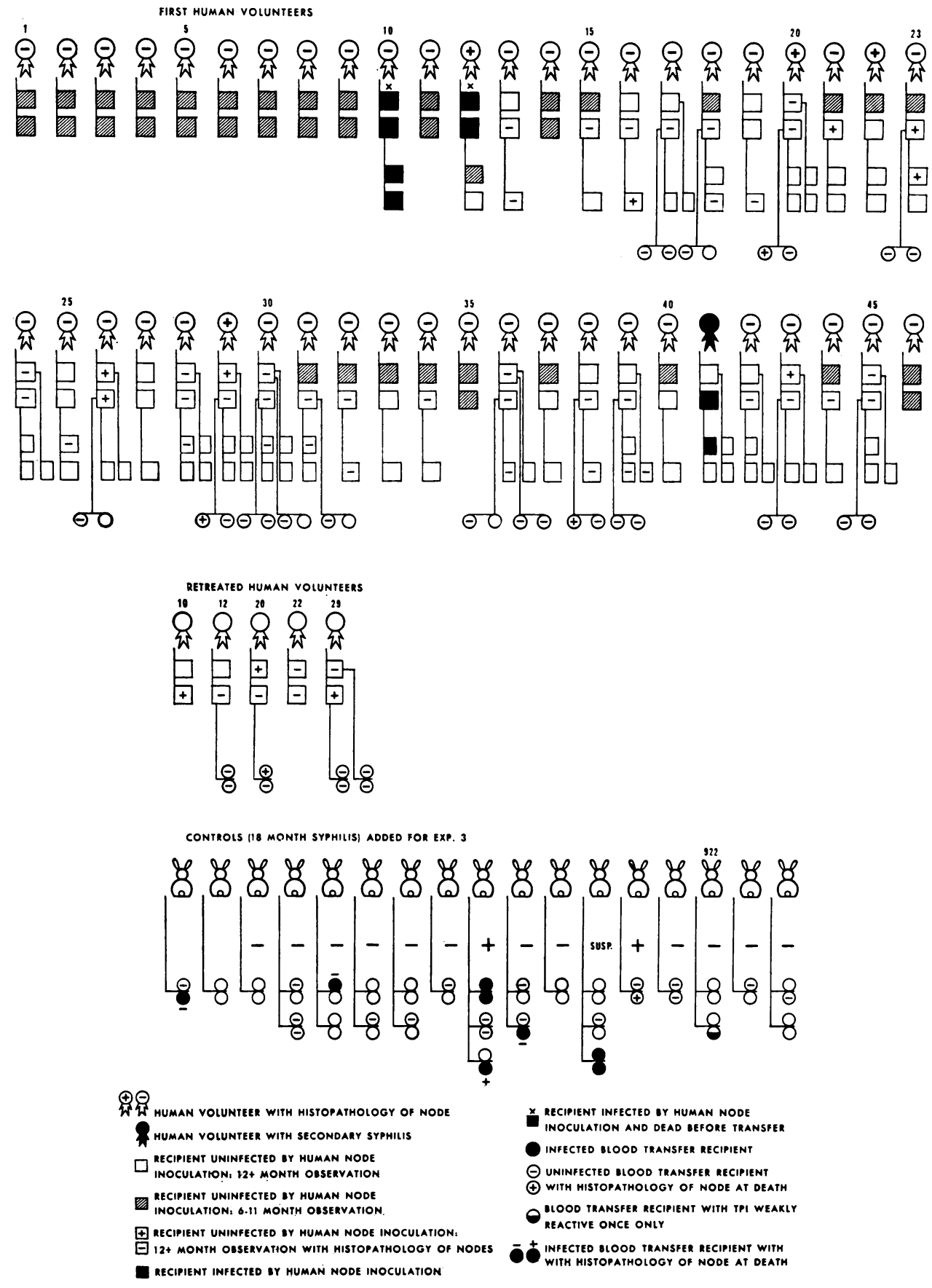

Chart 2.-Human studies. Experiment 2. Cortisone effect on rabbit recipients of human nodes. Experiment 3. 


\section{Continued Studies of Material from Humans}

METHOD A 6-month observation period was originally planned for animal recipients of the human lymph nodes. This was extended to 12 months when two of those recipients developing darkfield-positive orchitis showed atypical serological response (non-reactive TPI at 6 months), even though microscopical study of the four histologically positive human nodes had shown several fields with numbers of treponemes. After 12 months, the recipients of nodes from Patients 10 and 12 were still the only ones obviously infected. In an effort to detect latent infections, popliteal nodes from the $\mathbf{4 2}$ survivors (representing 32 patients) were then transferred to additional sero-negative rabbits which were also followed for 12 months by the routine described. Recipients of lymph nodes from the re-treated patients were not included, since the prescribed 12-month observation had not been completed.

\section{Results}

The node of one animal, inoculated with nodal material from an original recipient of the node of Patient 23, was shown to contain treponemes by FA staining but gave no clinical or serological evidence of overt infection. All other animal transfer and histopathological studies of material from this patient had been negative.

Experiment 3 Cortisone Effect on PenicillinTreated Late Latent Experimental Syphilis in Rabbits and on Rabbit Recipients of Human Nodes (Charts 1 and 2)

To alter the immune response so that latent disease, if present, might become manifest, cortisone was given to all surviving test animals from Experiments 1 and 2 and to appropriate controls. The course of cortisone was started 16 to 18 months after inoculation of the first human nodes into rabbits and 13 months after nodes from the retreated humans had been transferred to rabbits. In the penicillin-treated rabbits the time lapse from infection was 30 to 36 months, and from treatment 16 months. A new group of rabbits with untreated syphilis of 16 to 18 months' duration served as controls for the recipients of human nodes. Eight untreated rabbits with syphilis of 30 to 36 months' duration were added to the controls for the penicillintreated animals.

METHOD Sera from all control animals were examined by the VDRL and TPI tests before cortisone was started, and all controls were TPI-reactive. The test animals had all recently undergone serological testing and were not retested at this time. The 91 rabbits which received cortisone were the fifteen treated with penicillin and their seventeen controls, together with the 34 primary recipients of the original human nodes, and the eight recipients of nodes from the re-treated humans and their seventeen controls. Aqueous cortisone acetate (Merck, Sharp, and Dohme), at a dose of $5 \mathrm{mg}$. $/ \mathrm{kg}$./day, was injected into the muscle of the upper part of the back legs for 28 days or until death. For 14 days, the dose was given as a single injection; thereafter the dose was divided into two equal daily injections because an unexpectedly high animal mortality threatened the completion of the study.

TEST OF INFECTIVITY Since both popliteal nodes had been removed from the animals of Experiment 1, infectivity was now determined by blood transfer. As an infectivity control for the procedure, $1 \mathrm{ml}$. blood, drawn from each animal in the two control and the penicillintreated groups before cortisone was begun, was inoculated into each testis of two fresh, TPI-non-reactive, normal rabbits. Blood transfer of all animals was planned after the completion of cortisone treatment, but because of the high rabbit mortality during the course of cortisone, blood was transferred from all survivors after 14 and 28 days' treatment. The blood samples were tested by VDRL and TPI procedures. Blood was transferred from 43 animals at 14 days and from seven at 28 days. All blood recipients were followed for 12 months as outlined. When possible; popliteal nodes were removed at death from all cortisone-treated animals of the human study and axillary and inguinal nodes were taken from animals in the penicillin-treated group. In addition, popliteal nodes were also excised from all blood transfer recipients dying in less than 12 months. These nodes were examined microscopically. Nodes from animals completing observation were also studied as time permitted.

\section{Results}

Judged by the development of darkfield-positive orchitis or the appropriate serological response or both, infections were produced in the recipients by blood from ten control animals. These were as follows: four of the seventeen animals with untreated syphilis of 30 to 36 months' duration (one before cortisone, one after 14 days' treatment, and two after 28 days' treatment); and six of the seventeen with untreated syphilis of 18 months' duration (three before cortisone, and two each after 14 and 28 days' treatment). One donor, No. 873, caused infection both before and after treatment with 28 days' cortisone. Infection from two of the ten controls (Nos. 488 and 922) was manifested only by the development 1 year later of a weakly-reactive result to the TPI test in each recipient. Blood from penicillin-treated rabbits and from rabbits which had received human nodes did not cause infection.

One recipient of blood from the 30- to 36-month syphilis controls showed treponemes in its lymphoid tissue by FA staining, while its partner had previously developed overt infection. The node of one recipient of blood from the penicillin-treated group was also positive for treponemes by FA staining. 
Treponemes were not demonstrated in nodes of any other blood recipients in these two groups. Nodes of two recipients of blood from the 18-month syphilis control group contained treponemes on FA staining, and one of these animals developed obvious infection. Nodes of two non-paired recipients of blood from rabbits inoculated with human node tissue were shown by FA staining to contain treponemes; originally, these two human nodes had been positive for treponemes microscopically. Silver stain of the node of one blood recipient of the treated human group showed treponemes, while FA study of this node was negative although highly suspicious.

The cortisone-treated animals showed no change in serological response. After cortisone, FA staining of inguinal nodes of one control and of two penicillintreated rabbits from Experiment 1 showed treponemes, but blood from these animals did not infect. The node of one additional penicillin-treated rabbit which had died several days before the start of the cortisone study was positive only by silver stain; blood was not transferred. Treponemes were demonstrated by FA staining in the popliteal nodes of two 18-month control animals, after cortisone treatment. Blood from one of these control animals (No. 873) infected pre- and post-cortisone recipients and the node of the latter recipient was also positive by FA staining. Blood from the other control animal did not produce active infection, but its pre-cortisone recipient's node had contained treponemes. The node of one other 18-month control animal whose blood caused infection after cortisone treatment contained atypical spiral forms seen by silver stain. Six rabbits inoculated with human node tissue (two representing the same patient) harboured treponemes as shown by FA staining of nodes after cortisone. Two of the six surviving to blood transfer gave negative results in each case; the 12-month node transfer recipient of one of these had been positive by FA staining. Partners of two of the six had negative nodes after cortisone and survived for blood transfer studies; a recipient of one of these was positive by FA staining. Nodes from three recipients of the human nodes from re-treated patients were also FA-positive with no positive findings in blood recipients; however, the partner of one of these three had a blood recipient whose node was positive by silver stain.

During the course of cortisone treatment, one control donor rabbit (No. 488) developed a lesion on the dorsal surface of the right ear (identification numbers had been tattooed on the anterior surface of this ear), which was first noted on the 13th day of cortisone; this area was darkfield negative on numerous examinations and regressed during the treatment without other therapy. A scar persisted to the time of the animal's death 7 days after the completion of cortisone. Histopathology of the area at death showed increased fibrosis typical of scar formation but no indication of a recent syphilitic lesion; no treponemes were demonstrated.

\section{Experiment 4 Node Transfer to Cortisone-Treated Normal Rabbits}

METHOD In an attempt to determine the significance of the presence of immunochemically demonstrated treponemes without evident infectivity, a group of normal rabbits was given a 7-week course of cortisone acetate (Merck, Sharp, and Dohme); treatment consisted of two daily injections each of $2.5 \mathrm{mg}$. $/ \mathrm{kg}$. body weight given for 5 days, and then omitted for 2 days; this course was repeated for 7 weeks. Nodes from selected animals were injected into the testes of the normal rabbits after 10 days of cortisone, and treatment was continued 5 more weeks. Recipients were followed clinically for 7 months with darkfield examination of testicular aspirates and serological testing (VDRL at $1 \frac{1}{2}, 3$, and 7 months and TPI at 7 months.). Nodes were removed for histopathological study from animals dying before the end of the observation period and from animals completing observation, as time permitted.

A total of forty donors was selected from the following groups:

(1) Normal rabbits.

(2) Rabbits with natural Treponema cuniculi infection.

(3) Rabbits with untreated syphilis of 16 to 17 months' duration with a history of darkfield-positive lesions or serological reactivity or both (Blood transfer recipients of Experiment 3).

(4) Rabbits with late latent syphilis, 22 to 32 months after inoculation: some of these animals had been treated with curative amounts of spectinomycin (Upjohn) 8 to 17 months after infection and their untreated controls. Nodes from the cured animals had been FApositive 6 months after treatment when nodes were transferred.

(5) Negative blood recipients of FA-positive controls (Experiment 3).

(6) Negative recipients of blood from FA-negative donors whose partners had been FA-positive (Experiment 3). 
(7) Selected 12-month recipients of nodes transferred from animals which had been inoculated with human node tissue proved positive for treponemes by some procedure in the present group of studies (Experiment 2).

\section{Results}

Nodes from four of nine controls produced darkfield-positive disease in recipients; all four donors had been darkfield-positive earlier. Recipients of nodes from two control animals of the spectinomycin treatment group also developed darkfield-positive disease and appropriate serological response. Nodes from the $T$. cuniculi-infected animals produced darkfield-positive lesions on transfer, but the serological response of recipients was minimal to negative. No other recipients showed any indication of overt infection. TPI tests performed at 7 months were reactive only in those rabbits which had developed darkfield-positive lesions. No attempt was made to examine nodes from all these animals; however, histopathological examination on animals selected by chance from all seven groups showed treponemes by FA staining only in Groups 3, 5, and 6. Interestingly, the FA-positives in Group 6 represented Patients 12 and 20.

\section{Summary of Results}

Treponemes were demonstrated in four of 21 (19.0 per cent.) experimentally-infected rabbits after penicillin therapy. Although no overt disease developed, treponemes were successfully transmitted 12 months after penicillin treatment by node transfer from three animals ( $14 \cdot 3$ per cent.) and 18 months after penicillin by blood transfer from another ( 4.8 per cent.). Nodes from seven of eleven untreated controls (63.6 per cent.) with disease of the same duration produced darkfield-positive, serologically reactive disease in recipients, and blood from four of eleven controls ( $36 \cdot 4$ per cent.) with disease of 30 to 36 months' duration caused overt infection in recipients either before or after treatment with cortisone. Treponemes were present in the node of one other control in this group at death.

Eleven nodes from 45 men (24.4 per cent.) treated for syphilis at some time in the past were shown to harbour treponemes. Five human nodes (11.1 per cent.) were shown to be positive by successful animal transfer $(2=4 \cdot 4$ per cent.) or by microscopic study $(4=8.9$ per cent.); positivity of the other six (13.3 per cent.) was determined by microscopical study of tissues of subsequent animal recipients. Treponemes were demonstrated microscopically, after cortisone treatment, in nodes of six original animal recipients of material from five patients. The node of one of these patients had also been positive microscopically (silver stain).

Nodes from two rabbits inoculated 12 months previously with human node tissue contained transmissible treponemes demonstrable microscopically; one donor rabbit had been positive microscopically previously. Blood from rabbits representing three patients contained transmissible treponemes; two of these patients' nodes had been positive microscopically originally while this was the first positive finding for the third.

Nine of the eleven patients were positive only by microscopical study of human or rabbit nodes; four of the nine were positive more than once during the study.

Inoculation of nodes from two previously-treated patients and from the patient with secondary syphilis infected rabbits; only two of these infected on subtransfer.

Animal transfer of nodes from the five humans whom we had re-treated did not produce overt infection and microscopical study of the human nodes was negative. Microscopical study of nodes from the original rabbit recipients was positive in three ( 60 per cent.), and blood from the partner of one of these transmitted treponemes after cortisone therapy. Therefore, the animal study of one of the five human nodes ( 20 per cent.) was positive in the two different steps.

Three controls with syphilis of 18 months' duration caused overt infection and one caused microscopical infection after blood transfer before treatment with cortisone; four infected overtly after cortisone, and one of these four was also microscopically positive. Nodes from two of fifteen controls were positive and one suspicious after cortisone treatment (20 per cent.). Three controls with syphilis of 18 months' duration were positive twice or more in subsequent study.

Nodes from normal rabbits, from rabbits with proven cuniculosis, and from syphilitic rabbits treated in the late latent stage with spectinomycin produced no overt infection in rabbits prepared by cortisone treatment; pathological studies of nodes from selected recipients were negative for treponemes.

\section{Discussion}

The need for a rapidly effective non-toxic therapeutic agent for syphilis was apparently met by penicillin. With the vast majority of patients clinical response was excellent, with rapid regression of the 
lesions, almost immediate clearing of motile treponemes, and serological conversion as determined by reagin tests. Indeed, cure was so rapid and easy that re-infection became a problem and a new clinical syndrome, "ping-pong syphilis", was recognized in which sex partners treated individually continued to re-infect each other until both were treated simultaneously (Stewart, Thomsen, and Gardner, 1951). The incidence of infectious syphilis declined without an increased incidence of neurosyphilis or other complications of late syphilis (VD Fact Sheet, 1965).

Penicillin was purified, and the development of new long-acting preparations reduced the number of injections required (USPHS, 1960). The antibiotic produced clinical cure of infection, but did not repair damaged tissues.

For almost 20 years there was no clinical evidence suggesting that $T$. pallidum was developing resistance to penicillin, though other micro-organisms developed marked resistance to this and to other antibiotic agents (Finland, 1955).

The development of procedures such as the Reiter protein complement-fixation (RPCF) (Cannefax and Garson, 1957) and Treponema pallidum immobilization (TPI) (Nelson and Mayer, 1949) tests, showed that, although reagin usually returned to nonreactive levels after treatment, the specific antibody response continued, often until death (Rockwell, Yobs, and Moore, 1964).

In reports in the years 1962 to 1965 , Collart and co-workers (1962-65), proposed to explain the persistence of immobilisins by the continued presence of treponemes after penicillin treatment. They demonstrated treponemes in silver-stained smears of nodes from nine humans who had been treated repeatedly, and transfer of these nodes to rabbits proved that three were still infectious. Two of twelve rabbits treated in late latency with penicillin developed granulomatous lesions of the ear when they were given a course of cortisone 12 months later. Treponemes consistent with $T$. pallidum were present in silver-stained smears from the lesion of one animal only; findings in the other were inconclusive. Asymptomatic re-infection or inadequate treatment, due either to insufficient penicillin or to unrecognized antagonism between the combined therapeutic agents, offered logical explanations of their findings in humans. Results of studies with individually caged rabbits were more difficult to explain.

Del Carpio (1963) reported that, while nodes from four rabbits treated with 1.5 million units penicillin for syphilis of 2 months' duration were not infectious, nodes from rabbits similarly treated 8 to 16 months after infection produced TPI conversion in recipients. Recently, Boncinelli, Vaccari, Pincelli, and Lancellotti (1966) demonstrated T. pallidum by silver stain in a lymph node from one of eight humans with primary or secondary syphilis some 6 to 54 days after treatment with 15 million units penicillin either alone or in combination with bismuth. They also reported finding typical $T$. pallidum in the nodes of four of eight patients with late latent or neurosyphilis previously treated with arsenic, bismuth, and penicillin; node transfer resulted in no overt infections, but one recipient became TPI-reactive.

The investigation we report had two facets-one concerned a group of humans with a history of treatment for naturally-acquired or congenital syphilis, and the other concerned a group of rabbits experimentally infected with Nichols virulent strain $T$. pallidum and treated with penicillin in late latency. While strains of $T$. pallidum in the human reservoir may have had some exposure to sub-curative levels of antibiotics through the treatment of concurrent illnesses in syphilitic patients, the Nichols strain has had no such exposure. This standard laboratory strain has been maintained for more than 50 years by passage through rabbits never exposed to antibiotics.

On the basis of the results of node transfer, rabbits with late latent syphilis were apparently cured by penicillin treatment while untreated rabbits remained infectious. Negative results in node studies after 12 months in some of the control group were explicable by the small numbers of treponemes thought to be present in late latent syphilis (Bessemans, Van Haelst, and DeWilde, 1935). After cortisone treatment, staining showed nodes from three penicillin-treated rabbits and one bloodtransfer recipient to be positive for treponemes. On the other hand, four recipients of blood from control rabbits developed darkfield-positive sero-positive syphilis; one developed (from No. 488) sero-positive syphilis only; and one was positive only by staining. These recipients represented four different control animals; one other control was positive only by histopathology of its own node.

Results in the human study did not agree with the generally accepted concept of the response of syphilis to penicillin. Initially, five, eventually eleven, of the 45 men with treated syphilis were shown to be positive by some study procedure; nodes from only two men produced overt clinical infection in rabbits. The medical data of these eleven are summarized in Table $I$. The clinical data of the remaining patients have been published (Yobs and others, 1964a). 
A group of TPI-reactive prisoners with medical histories of at least some reliability were studied. However, they had last been treated for syphilis at least one and generally several years previously, and the possibility of re-infection could not be absolutely excluded. The five men initially positive were interviewed for possible contacts, re-treated, and re-studied in an attempt to relate the earlier findings either to re-infection or to inadequate treatment (Yobs and others, 1964a). While study procedures on the post-retreatment nodes were all negative for 12 months, after cortisone treatment, the nodes from rabbit recipients of these human nodes and their blood transfer recipients, representing three of the re-treated patients, were shown to contain treponemes by histopathological techniques.

When a person adequately treated for syphilis is re-infected, he may develop a darkfield-positive lesion, depending on the stage at which the earlier infection was treated. Generally, a temporary increase in reagin antibody is detectable, although the duration and degree of this rise is variable. While the histories of the 45 men did not absolutely rule out re-infection, their serum test results had been stable with no sudden or significant fluctuations since the last treatments; certainly, the results in those whom we re-treated showed no change such as might occur after the treatment of active syphilis (Yobs, Olansky, Rockwell, and Clark, 1965). Despite this, three of five nodes removed after re-treatment were eventually shown to contain treponemes.

It has been difficult to correlate the positive findings by staining in nodes of humans and rabbits with the failure to infect. Prolonged darkfield examination of human node suspensions showed no typical motile treponemes and only one non-motile treponemal form. The three human nodes positive by FA-staining showed several fields with three to five or more treponemes; silver stain showed fragments of several treponemes in one node. Yet, only two human nodes produced overt infection and one of these had been negative by histopathological study.

The treponemes isolated from Patients 10 and 12 were apparently less virulent for rabbits in early passages than the Nichols virulent strain of $T$. pallidum; darkfield-positive lesions developed more slowly and were generally more transient. Recipients did not show the anticipated serological response; those surviving 6 months were TPI-non-reactive and VDRL-non-reactive or reactive in low titre. Both isolates were carried through several subsequent

TABLE II

RABBIT PASSAGE OF TREPONEMA PALLIDUM ISOLATES FROM TWO PATIENTS

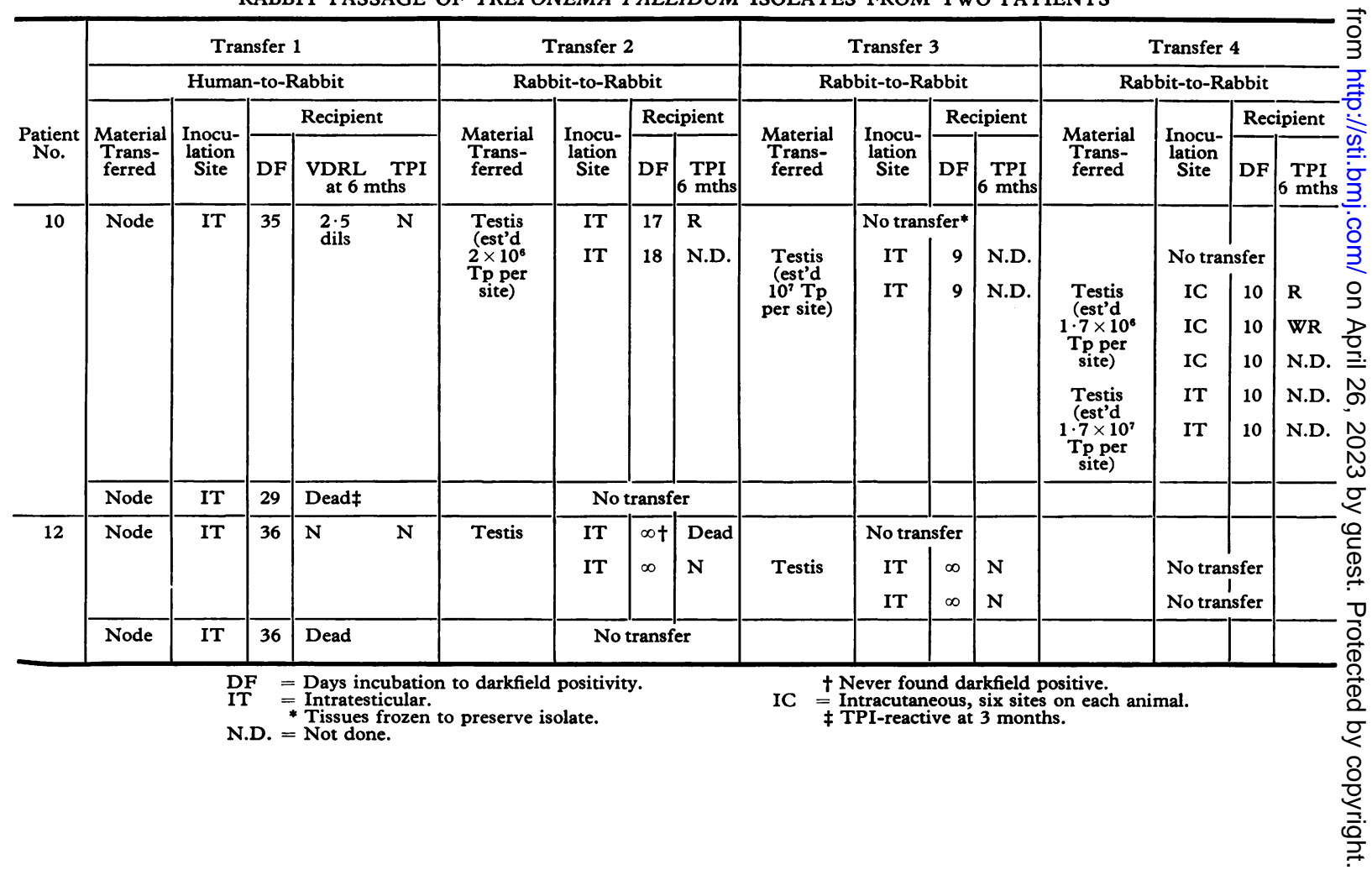


transfers (Table II). The isolate from Patient 12 was immediately lost, but that from Patient 10 has had eight animal passages, during which it either adapted to the new host species with increased virulence or the numbers transferred increased and stabilized. Whatever the reason, the development of darkfield positivity and of measurable treponemal antibody has been more predictable in these later passages of this strain.

Brown and Pearce (1920) stated that most investigators were of the opinion that the virulence of $T$. pallidum for rabbits might be increased by passage or by adaptation, but that the time for which this increase might be kept up or the extent to which it might be carried was unknown. Chesney suggested that adaptation to a new host might be an important factor in the failure of some animals to develop overt disease (Chesney and Kemp, 1925).

Determination of the virulence of demonstrable treponemes has been a primary consideration in these studies. Since individual host variation is recognized as an important factor in the successful demonstration of virulence, the original study was expanded to include intensive efforts to demonstrate virulence by prolonged observation, by subtransfer to other animals, and by alteration of host response. Twelve months' observation of human node recipients and penicillin-treated rabbits followed by subtransfer showed no additional rabbits with symptomatic infection, but one subtransfer recipient's node was shown by FA-staining to contain a spiral organism which resembled $T$. pallidum.

Cortisone treatment may lower the natural and acquired resistance of laboratory animals to certain infections (Fischel, 1952); however, cortisone alters the host's immune system in a complex manner not as yet wholly understood (Turner and Hollander, 1950, 1954; Delamater, Sauzino, and Urbino, 1952). In experimental syphilis in rabbits, cortisone greatly enhances the infection when administered during the time the disease is developing (Turner and Hollander, 1950, 1954; Delamater and others, 1952; Germath, Ottinger, and Oyama, 1952). Its effect on the titre of circulating antibodies in early syphilis has not been clearly defined, but preliminary studies indicated that the development of TPI antibody was not affected. Collart and others (1962a) found that disease in penicillin-treated latent syphilitic rabbits was more manifest after cortisone treatment.

McLeod and Magnuson (1956) gave cortisone to thirty rabbits with experimental syphilis of 7 to 9 months' duration at a dose of $5 \mathrm{mg}$. $/ \mathrm{kg}$./day for 29 days; eighteen survived the entire course. One month after the injections, one of the cortisone- treated rabbits had an infectious relapse as shown by the development of a darkfield-positive nodular lesion in scar tissue on the ear. Such infectious relapses are extremely rare (Pearce, 1938). The infectivity of blood from these animals was enhanced; blood from 75 per cent. of the cortisonetreated animals was infective compared with only 41 per cent. of the controls. The same authors gave cortisone to twelve rabbits with syphilis of 12 to 18 months' duration at a dose of $10 \mathrm{mg}$./kg./day, for 17 days; no lesions developed but the VDRL titre decreased more than 2-fold or reverted to negative. Although the cortisone was given in the smaller dose schedule used by McLeod and Magnuson (1956), it was soon obvious that the apparently healthy rabbits in our study, syphilitic control or test, were extremely sensitive to this regimen. However, our study has revealed no data to indicate significant influence by cortisone on the course of late latent treated experimental syphilis in rabbits or on the receptivity of rabbits to infection.

Removal of inguinal or axillary nodes or both without killing the animal was not practicable in this laboratory; therefore, since both popliteal nodes had been removed from some animal groups, infectivity after cortisone therapy was determined by blood transfer. This procedure had been used as a measure of infectivity by Frazier, Bensel, and Keuper (1950) who showed that spirochaetaemia persisted in rabbits for as long as 1,287 days after inoculation with Nichols strain T. pallidum; their data suggested that the organisms were not present in the blood continuously (Frazier, Bensel, and Keuper, 1952). In our experiments, blood from four of seventeen controls (23.5 per cent.) with syphilis of 30 to 36 months' duration and from six of seventeen controls ( 35.3 per cent.) with syphilis of 18 months' duration caused infection. Frazier and his co-workers showed that blood from eleven of 31 rabbits (41 per cent.) with asymptomatic infections for over 24 months harboured T. pallidum, and two of these animals had been in latency for over 3 years when their blood was found to be infectious. On the basis of dissimilar response in paired recipients (only one becoming infected), they concluded that the number of spirochaetes in the blood at this time was small, and they suggested that when only one of a pair of recipients identically inoculated developed disease, the number of organisms in the inoculum was insufficient to overcome the natural resistance of the one recipient. They showed that blood from animals with negative serological tests could be infectious.

The use of histopathological techniques complicated the interpretation of the results of this study. There is little agreement on the morphological 
criteria for identification of $T$. pallidum in fixed preparations. Most knowledgeable persons prefer to accept only "typical" forms, i.e. those on which everyone will agree, although the finding of atypical forms in darkfield preparations is a recognized occurrence. Silver staining is technically difficult to perform and equally difficult to interpret since it is not a specific stain. Immunochemical techniques, while considerably more specific, incorporate subjective evaluation of fluorescence intensity. Also, treponemal "group" antigens (Deacon and Hunter, 1962) and similar antigens in other groups of microorganisms which may stain may present problems.

The fluorescein-conjugated rabbit antiserum to $T$. pallidum, which was used in the direct fluorescent antibody technique for the demonstration of treponemes, was prepared in our laboratories according to the procedure described previously (Yobs and others, 1964b). Some pilot work was performed by staining $T$. pallidum with conjugate absorbed with the sorbing agent developed for the fluorescent treponemal antibody-absorption (FTAABS) serological test (Hunter, Deacon, and Meyer, 1964). This sorbent reduces and frequently eliminates the staining of "group" treponemal antigens common to many treponemes, including the known nonpathogenic, cultivable ones (Deacon and
Hunter, 1962). However, since the sorbing agent was not readily available during this study and since a change in staining procedure would have added another variable, sorbed conjugate was not used in this study for the FA-staining of treponemes. All fluorescent stained material was read without identification of source by one of the authors; positives were confirmed by at least two other microscopists, also reading without specimen identification. Negative preparations were not routinely examined by more than one microscopist.

A large number of the positive results in this study were based on the demonstration of treponemes in nodes which produced no detectable disease on inoculation into normal rabbits. Evaluation of the sensitivity and specificity of the fluorescent staining procedure with this conjugate in the demonstration of $T$. pallidum was, therefore, undertaken. Materials studied included lymph node and testicular tissues and aspirates and exudate from skin chancres of rabbits, humans, and the Aötus trivirgatus monkey. Results summarized in Table III show that while exudate from primary and secondary lesions of rabbits and humans are positive for treponemes by this method, lymph nodes were not found positive until more that 6 months after inoculation and were not consistently positive then. Darkfield-positive

TABLE III

DEMONSTRATION OF TREPONEMA PALLIDUM BY FA-STAINING COMPARED WITH INFECTIOUSNESS IN NODE TRANSFER PROCEDURE

\begin{tabular}{|c|c|c|c|c|c|c|c|}
\hline Species & \multicolumn{2}{|c|}{ Condition } & $\begin{array}{l}\text { Material } \\
\text { Stained }\end{array}$ & $\underset{\text { FA+ }}{\text { No. }}$ & $\begin{array}{l}\text { Node Transfer } \\
\text { (No. infecting/ } \\
\text { No. transferred) }\end{array}$ & $\begin{array}{l}\text { No. } \\
\text { FA- }\end{array}$ & $\begin{array}{l}\text { Node Transfer } \\
\text { (No. infecting/ } \\
\text { No. transferred) }\end{array}$ \\
\hline \multirow[t]{8}{*}{ Rabbit } & \multicolumn{2}{|l|}{ Normal } & Node & 0 & N.D. & 7 & N.D. \\
\hline & \multicolumn{2}{|c|}{ Normal + cortisone } & Node & 0 & N.D. & 11 & N.D. \\
\hline & \multirow{3}{*}{ Primary syphilis } & & Lesion exudate & 20 & N.D. & 6 & $1 / 1$ \\
\hline & & Adequately treated* & Nodet & 0 & $0 / 0$ & 18 & $0 / 12$ \\
\hline & & Inadequately treated * & Nodet & 0 & $0 / 0$ & 5 & $1 / 1$ \\
\hline & \multirow[b]{2}{*}{ Late syphilis } & $14 \cdot 32$ mths Untreated & Node $\neq$ & 5 & $2 / 3$ & 13 & $6 / 11 \S$ \\
\hline & & $\begin{array}{l}\text { Adequately treated* } \\
7 \text { mths after } \mathbf{R x} \\
8-12 \text { mths after } \mathbf{R x} \\
13+\text { mths after } \mathbf{R x}\end{array}$ & Node $\ddagger$ & $\begin{array}{l}5 \\
3 \\
1\end{array}$ & $\begin{array}{l}0 / 5 \\
0 / 3 \\
0 / 1\end{array}$ & $\begin{array}{r}10 \\
3 \\
6\end{array}$ & $\begin{array}{l}0 / 10 \\
0 / 3 \\
0 / 6\end{array}$ \\
\hline & \multicolumn{2}{|l|}{ T. cuniculi } & $\begin{array}{l}\text { Lesion exudate } \\
\text { Node }\end{array}$ & $\begin{array}{l}0 \\
0\end{array}$ & $\begin{array}{l}0 / 0 \\
0 / 0\end{array}$ & $\begin{array}{r}5 \\
17\end{array}$ & $\begin{array}{l}2 / 2 \\
5 / 8\end{array}$ \\
\hline Man & \multicolumn{2}{|c|}{ Secondary syphilis } & $\begin{array}{l}\text { Lesions and } \\
\text { exudate }\end{array}$ & 4 & $2 / 4 \|$ & 0 & $0 / 0$ \\
\hline \multirow[t]{2}{*}{ Monkey } & \multicolumn{2}{|l|}{ Normal } & Node & 0 & N.D. & 2 & $0 / 2$ \\
\hline & \multicolumn{2}{|c|}{ Strain from humans } & $\begin{array}{c}\text { Darkfield }+ \\
\text { node aspirate }\end{array}$ & 0 & $0 / 0$ & 2 & $2 / 2$ \\
\hline
\end{tabular}

N.D. = Not done.

* Treatment consisted of varying amounts of spectinomycin.

+ Node removed 6 months after completion of treatment.

$¥$ Node removed at times indicated.

Five infected only one of two recipients.

II Lesion tissue not node suspended and inoculated. 
material from rabbits with natural cuniculosis did not stain. Treponemes were also demonstrated in the small group of infected monkeys studied by this procedure. It appears, therefore, that while FAstaining is a specific procedure, it neither reflects virulence nor possesses a high degree of sensitivity. The stained material must still contain morphologically typical spiral forms to be presumed positive for treponemes and the procedure does not definitely identify the treponeme as $T$. pallidum.

It has been difficult to correlate positive microscopic findings in nodes with non-infectiousness on transfer. These forms probably are not artefacts since their morphology and immunochemical staining were typical of $T$. pallidum. If these were $T$. pallidum killed by treatment, they had been dead for some time and would have been subject to phagocytosis or degenerative changes. Saprophytic treponemes have not previously been recognized in nodes or blood in such numbers; in fact, Public Health Service instructions (USPHS, 1962) suggest examination of aspirated material from a regional node to establish a darkfield diagnosis when the demonstration of $T$. pallidum in lesion exudate is unsuccessful.

The possibility must be considered that these fluorescent treponemes in recipient rabbits may have been $T$. cuniculi. All rabbits in this study were carefully examined for lesions suggesting this endemic treponematosis before initial use and regularly thereafter, and each rabbit also underwent VDRL and TPI tests before use and periodically thereafter. All baseline studies were negative, and there was no clinical suggestion of cuniculosis in these animals or others in this colony. In this study, treponemes stained with an intensity typical for $T$. pallidum; darkfield-positive material from natural cuniculosis lesions in a separate colony showed significantly less fluorescence when stained by the same procedure. In fact, the staining of $T$. cuniculi was so faint as to be termed "negative" in blind readings when slides of both $T$. pallidum and $T$. cuniculi were included. With experimental passage of the $T$. cuniculi strain, staining became more intense and virulence increased as shown by more rapid and predictable lesion development (Clark and Yobs, unpublished).

Accumulated data suggest that the organism detected in this study by FA-staining was not only propagating without causing lesions or detectable serological response but was also transmissible in suspension to new hosts with the same effect.

If it is accepted that altered $T$. pallidum of decreased virulence can persist after the antibiotic treatment of late latent syphilis, questions must be resolved which concern the mechanism of the altered virulence, the cause of the persistence, the antigenic significance of these organisms and their influence on the pathogenesis of clinical syphilis. One approach is through considering the mode of action of antibiotics. Penicillin has been shown to kill Gram-positive bacteria more readily than Gramnegative ones (Fleming, 1929). It acts on growing cells but not resting ones (Hobby, Meyer, and Chaffee, 1942), resulting in the formation of large or filamentous forms of bacteria (Gardner, 1940; Duguid, 1946). Lederberg (1956), working with bacilli, showed that penicillin selectively inhibited bacterial cell wall synthesis without causing lethal effect on protoplasts; the growing protoplasts continued to enlarge in its presence and reverted to bacilli when the penicillin was removed. The continued enlargement of the protoplast explains the requirement of growth for penicillin action, since the growing protoplast emerging through a break in the wall is then subject to different osmotic pressures. Unless this occurs, the protoplast remains a stable form within the cell wall, eren though cell wall synthesis may have been blocked by penicillin. Antigens present in intact portions of the cell wall continue to function.

Magnuson, Eagle, and Fleischman (1948) estimated that $T$. pallidum has a multiplication time for one generation of some 33 hours. If such a slow process permitted the protoplast to remain entirely within the cell wall, or if the protoplast were sufficiently elastic to adjust to minute osmotic differences in its environment, rupture and death might not occur. Similarly, if during therapy the extra-cell wall protoplast met an isotonic or hypertonic situation, rupture and death would not occur. It seems possible that the treponeme may also be genetically altered so that its virulence is affected, or that its virulence may be dependent on an intact cell wall.

Erythromycin has been shown to inhibit protein synthesis selectively in Escherichia coli (Brock and Brock, 1959); although the precise mode of action is unclear, other data suggest that this interference results from interaction with a ribosomal component (Wolfe and Hahn, 1964). Recently spectinomycin has also been shown to inhibit protein synthesis in $E$. coli cells and extracts, possibly also by action on ribosomes (Davies, Anderson, and Davis, 1965).

Another factor in the finding of treponemes after treatment may be failure of the antibiotic to penetrate to all parts of the host and to come into contact with all treponemes, but this seems unlikely. While tissue concentration requirements for cure of 
syphilis may vary between drugs, $T$. pallidum has been shown to be extremely sensitive to minute amounts of penicillin in vivo and in vitro and somewhat less sensitive to other agents.

Although the effect on bacteria of penicillin and other antibiotics is being studied by numerous investigators, little or no work has been reported on the effects of these agents on the host's cells. Toxicity has been evaluated, but metabolic and genetic effects are generally unknown. It is possible that some obscure enzyme system in the host's cells may be altered resulting in the continuation of an established antibody response or the inhibition of development of a detectable response.

Antibodies developed during the course of syphilis may alter $T$. pallidum, rendering it less virulent but still transmissible and demonstrable. Eberson (1921) showed that syphilitic serum possesses treponemicidal properties. Chesney and Kemp (1926) produced subclinical re-infection upon challenge of immune animals. Many investigators as well as the present authors (Morgan, 1941; Clark and Yobs, unpublished) have observed supposedly normal rabbits which did not develop darkfield-positive lesions and/or reactive serology after inoculation with large numbers of virulent $T$. pallidum while other rabbits inoculated simultaneously with identical inocula did develop syphilis. These observations suggest that antibodies affecting the virulence of the organism may develop.

Although the human volunteers, the penicillintreated rabbits, and the control rabbits were all TPI-reactive, nodes from all animals in these groups were not positive for $T$. pallidum. Animals in which treponemes were demonstrated by FA staining did not become VDRL-reactive or TPI-reactive unless they had also developed darkfield-positive syphilis, and at least one TPI-reactive control, positive by FA-staining reverted to TPI-nonreactive during this study. Therefore, the organisms which have been demonstrated by FA methods are probably not responsible for the persistence of immobilisins; certainly, they have not been able to initiate development of immobilisins to a measurable degree.

However, these organisms do remain at least partially intact antigenically as indicated by their ability to stain in the FA procedure. They also retain sufficient antigenicity to stimulate some antibody formation, as shown in a small retrospective study of baseline and final sera from some of the recipients of the eleven positive human nodes and the recipients of nodes positive for treponemes from penicillintreated rabbits. Although TPI and VDRL tests were consistently nonreactive, the FTA-ABS tests
(Hunter and others, 1964) performed on baseline sera, using fluorescein-labeled anti-rabbit globulin, were nonreactive while those on final sera were reactive. In another study on rabbits inoculated intracutaneously or intratesticularly with large numbers of $T$. pallidum, FTA-ABS reactivity was detected 1 week after inoculation (Mothershed, Yobs, and Clark, 1967). The organisms detected by staining in this study may also stimulate the production of antibody(s) not detectable with available serological test procedures and antigens.

If Treponema pallidum or treponemes derived from $T$. pallidum continue to live and apparently to multiply in the host after treatment, it seems logical to consider that they must have some role in the pathogenesis of clinical syphilis. The persistence of virulent $T$. pallidum would probably be hazardous to the patient and, if proved, would justify anticipation of a resurgence of late manifest syphilis. As in tuberculosis, a state of immunity with delayed hypersensitivity may develop in which a new exposure to treponemes triggers renewed clinical activity and late manifestations. The occurrence of such a hypersensitive state was indicated in an earlier study (Magnuson, Thomas, Olansky, Kaplan, De Mello, and Cutler, 1956) in which it was shown that patients who have once had syphilis, even though cured in the primary stage, are never the same immunologically. Their serological response to re-infection is typical of those observed in anamnestic rises due to other antigenic stimuli. Also, if the previous infection was of sufficiently long duration, it produced considerable resistance to subsequent challenge. It is interesting to speculate about the formation and importance of a treponeme-host complex and an auto-immune response to the host portion of the complex. Of course, these "altered" treponemes may simply invade appropriate tissues of susceptible hosts where multiplication occurs slowly with the development of late lesions depending on exo-effects of the treponemes or metabolic products.

If the demonstrated treponemes are not accepted as altered $T$. pallidum, then they must be explained in some other way. Several possibilities have already been considered. It is interesting to speculate about others. The FA-positive treponemes present in recipients without overt infection may not be $T$. pallidum at all but nonvirulent treponemes with the same or a related antigenic mosaic. One may hypothesize, although there is no supporting evidence at present, that $T$. pallidum is symbiotically dependent on these for nutritional or other support to maintain existence or virulence. If conditions were not favourable to the biochemical functions 
necessary for symbiosis, virulence might be affected; and one or both treponemes might conceivably be lost, even though the original inoculum had contained both. Or it may be postulated that these are $T$. pallidum rendered avirulent by alteration of molecular biology through either mutation or as yet unidentified chemical action.

One may also speculate that $T$. pallidum has a life cycle in only one stage of which the recognized treponemal morphology is found and in only one stage of which the organism is sensitive to antibiotics. Many scientists, notably Delamater, Newcomer, Haanes, and Wiggall, 1950; Delamater, Haanes, Wiggall, and Pillsbury, 1951, and Levaditi, Schoen, and Sanchis-Bayarri, 1927; Levaditi and $\mathrm{Li}$ Yuan Po, 1930, have proposed the existence of a life cycle in which stages differ in morphological characteristics, but no one has proved that $T$. pallidum has such a cycle.

This research suggests that in syphilis, as in acute rheumatic fever, it may be possible to demonstrate the causative organism at various intervals after treatment when there is no clinical disease. Stollerman, Siegel, and Johnson (1965) have reported examining 1,000 patients with throat cultures positive for Group A betahaemolytic streptococci but without rheumatic fever; demonstrating in effect a carrier state. The significance of such a state has not been determined in either disease. The virulence of these organisms is unknown as is the requirement for the development of clinical disease where they are found. The magnitude of the immune response and the duration of convalescent carriage of streptococci seem to be related to the attack rate of rheumatic fever. Both are related to the virulence of the streptococcal strain. Interestingly, type-specific antibodies persist for as long as 32 years, and this persistence is not correlated with the severity of the streptococcal infection or the serological type of the infecting strain (Lancefield, 1959).

In the past, evaluation of a chemotherapeutic agent's efficacy in curing syphilis has been based on the clinical response to treatment and the infectivity of tissues transferred at some interval after treatment, as shown by the development of darkfieldpositive lesions and serological response in recipients. Because of technical difficulty and low sensitivity, failure of histological demonstration of $T$. pallidum has not been used as a criterion. Findings in this study do not conflict with these criteria; instead, they add a new dimension to the study of the pathogenesis and immunity of syphilis.

As often transpires, this study has posed more questions than it has answered. We have shown, as did the teams led by Collart, Del Carpio, and
Boncinelli, that a treponeme is present after antibiotic treatment in syphilitic humans and in individually caged, experimentally infected rabbits where re-infection is not a problem. However, in contrast to these investigators, we have not demonstrated disease-producing virulence, although we have shown infectivity in that we have recovered these organisms after blood and tissue transfer. The treponemes found in this study were present after antibiotic treatment with penicillin, erythromycin, or spectinomycin. While several possible explanations have been proposed, the results are not conclusive. The questions raised might be answered in two ways:

(1) A similar investigation of nodes from a group of humans with negative results to TPI tests and no history or indication of previous or current syphilitic infection;

(2) A determination of the virulence of treponemes present after treatment in recipients with permanently impaired immune mechanisms.

Both should include in vitro culture for treponemes, but large-scale studies are not necessary to secure the required data.

\section{Summary}

Nodes from eleven of 45 TPI-reactive male volunteers treated in the past for syphilis were shown to harbour treponemes. Nodes from three of five of these subjects were shown to harbour treponemes after re-treatment.

Four of 23 TPI-reactive rabbits with syphilis of 14 to 22 months' duration at the time of penicillin treatment were later shown to harbour treponemes.

Data presented suggest that these are probably $T$. pallidum of decreased virulence and altered antigenicity. Alternative conclusions and implications are discussed.

The authors wish to thank the Testing and TPI Units, Standardization and Consultation Services, Venereal Disease Research Laboratory, Venereal Disease Program, National Communicable Disease Center, Atlanta, Georgia, for performing serological tests on all human sera and cerebrospinal fluids and for performing the TPI testing on rabbits in this study.

\section{REFERENCES}

Bessemans, A., Van Haelst, J., and DeWilde, H. (1935). Amer. F. Syph., 19, 161.

Boncinelli, U., Vaccari, R., Pincelli, L., and Lancellotti. M. (1966). G. ital. Derm., 107, 1.

Brock, T. D., and Brock, M. L. (1959). Biochem. biophys. Acta, 33, 274.

Brown, W. H., and Pearce, L. (1920). F. exp. Med., $31,475$.

Cannefax, G. R., and Garson, W. (1957). Publ. Hlth Rep. (Wash.), 72, 335. 
Chesney, A. M., and Kemp, J. E. (1925). F. exp. Med., 42, 33 .

- - (1926). Ibid., 44, 589.

Clark, J. W., Jr., and Yobs, A. R. Unpublished data.

- - In preparation.

Collart, P. (1964). "Persistence of Treponema pallidum in Late Syphilis in Rabbits and Humans, notwithstanding Treatment", in "Proceedings World Forum on Syphilis and Other Treponematoses, Washington D.C., Sept. 4-8, 1962", p. 285. Public Health Service Publication No. 997. U.S. Communicable Disease Center. Venereal Disease Branch, Atlanta, Georgia.

Collart, P. (1965). Proph. sanit. morale, 37, 247.

- - Borel, L., and Durel, P. (1962a). Ann. Inst. Pasteur, 102, 596.

,$--\longrightarrow$, (1962b). Ibid., 102, 693.

—_- _- (1964). Brit. F. vener. Dis., 40, 81. and Durel, P. (1964). Ann. Derm. Syph., 91, 485.

Davies, J., Anderson, P., and Davis, B. D. (1965). Science, 149, 1096.

Deacon, W. E., and Hunter, E. F. (1962). Proc. Soc. exp. Biol. (N.Y.), 110, 352.

DeLamater, E. D., Haanes, M., Wiggall, R. H., and Pillsbury, D. M. (1951). F. invest. Derm., 16, 231.

- Newcomer, V. D., Haanes, M., and Wiggall, R. H. (1950). Amer. F. Syph., 34, 122.

, Saurino, V. R., and Urbach, F. (1952). Ibid., 36, 127.

Del Carpio, C. (1959). Riv. Ist. sieroter. ital., 34, 432. (1963). Ibid., 38, 166.

Dieterle, R. R. (1927). Arch. Neurol. Psychiat. (Chicago), $18,73$.

Duguid, J. P. (1946). Edinb. med. F., 53, 401.

Eberson, F. (1921). Arch. Derm. Syph. (Chicago), 4, 490.

Finland, M. (1955). New Engl. F. Med., 253, 909.

Fischel, E. E. (1952). In "Connective Tissues; Trans. 3rd. Conference, Josiah Macy, Jr., Foundation, N.Y.", p. 117.

Fleming, A. (1929). Brit. F. exp. Path., 10, 226.

Frazier, C. N., Bensel, A., and Keuper, C. S. (1950). Amer. F. Syph., 34, 453.

- - - (1952). Ibid., 36, 167.

Gardner, A. D. (1940). Nature (Lond.), 146, 837.

Germuth, F. G., Jr., Ottinger, B., and Oyama, J. (1952). Bull. Fohns Hopk. Hosp., 91, 22.

Hobby, G. L., Meyer, K., and Chaffee, E. (1942). Proc. Soc. exp. Biol. (N.Y.), 50, 281.

Hunter, E. F., Deacon, W. E., and Meyer, P. E. (1964). Publ. Hlth Rep. (Wash.), 79, 410.

Krajian, A. A. (1939). Amer. F. Syph., 23, 617.

Lancefield, R. C. (1959). F. exp. Med., 110, 271.

Lederberg, J. (1956). Proc. nat. Acad. Sci., 42, 574.

Levaditi, C., Schoen, R., and Sanchis-Bayarri ,V. (1927). Bull. Acad. Méd. (Paris), 3 sér 98, 149.

- and Li Yuan Po. (1930). C.R. Soc. Biol. (Paris), 104, 736.

McLeod, C. P., and Magnuson, H. J. (1956).F. Immunol., 76, 373.

Magnuson, H. J., Eagle, H., and Fleischman, R. (1948). Amer. F. Syph., 32, 1.

-, Thomas, E. W., Olansky, S., Kaplan, B. I., De Mello, L., and Cutler, J. C. (1956). Medicine (Baltimore), 35, 33.
Mahoney, J. F., Arnold, R. C., and Harris, A. (1943). F. vener. Dis. Inform., 24, 355.

,,$-- \quad$ (1949). Ibid., 30, 350.

Morgan, H. J. (1941). Amer. F. Syph., 25, 233.

Mothershed, S. M., Yobs, A. R., and Clark, J. W', Jr. (1967). Brit. F. vener. Dis., 43, 267.

Nelson, R. A., Jr., and Meyer, M. M. (1949). F. exp. Med., 89, 369 .

Pearce, L. (1938). In "Syphilis", ed. F. R. Moulton, Amer. Ass. Advanc. Sci. Publ. No. 6, p. 58.

Probey, T. F. (1948). Publ. Hlth Rep. (Wash.), 63, 1654. (1953). Amer.F. Syph., 37, 369.

Rockwell, D. H., Yobs, A. R., and Moore, M. B., Jr. (1964). Arch. intern. Med., 114, 792.

Stewart, J. J., Thomsen, J. G., and Gardner, R. K. (1951). Arch. Derm. Syph. (Chicago), 63, 136.

Stollerman, G. H., Siegel, A. C., and Johnson, E. E. (1965). Mod. Conc. cardiovasc. Dis., 34, 45.

Turner, T. B., and Hollander, D. H. (1950). Bull. Fohns Hopk. Hosp., 87, 505.

(1954). Amer. F. Syph., 38, 371.

U.S. Public Health Service (1960). Publication No. 743, "Syphilis: Modern Diagnosis and Management". Washington.

(Revised May, 1964) "S64). Publication No. 411 -1964 Manual". Washington.

"Darkfield Microscopy for the Detection and Identification of Treponema pallidum."

VD Fact Sheet (1965). Table 2.

Willcox, R. R. (1954). Bull. Wld Hlth Org., 10, 579.

Wolfe, A. D., and Hahn, F. E. (1964). Science, 143, 1445.

Yobs, A. R., Brown, L., and Hunter, E. F. (1964b). AMA Arch. Path., 77, 220.

, Olansky, S., Rockwell, D. H., and Clark, J. W., Jr. (1965). Arch. Derm. (Chicago), 91, 379.

, Rockwell, D. H., and Clark, J. W., Jr. (1964a) Brit. F. vener. Dis., 40, 248.

Des observations additionnelles au sujet de la persistance des Treponema pallida après traitement chez l'homme et le lapin RÉSUMÉ

Les ganglions lymphatiques de onze volontaires obtenus d'un nombre total de 45 hommes donnant une réaction positive au test TPI qui avaient été traités dans le passé pour la syphilis ont montré qu'ils hébergeaient des tréponèmes après un second traitement.

Quatre des 23 lapins réagissants au test TPI et atteints de syphilis d'une durée de 14 à 22 mois au moment où le traitement à la penicilline avait été commencé avaient montré plus tard qu'ils hébergeaient des tréponèmes.

Les données présentées suggèrent que ces tréponèmes étaient des $T$. pallidum de virulence diminuée dont l'antigénicité était changée. Plusieurs conclusions et leurs implications sont discutées. 